\title{
Reciprocal diversification in a complex plant-herbivore-parasitoid food web
}

\author{
Tommi Nyman*1, Folmer Bokma² and Jens-Peter Kopelke ${ }^{3}$
}

\author{
Address: ${ }^{1}$ Faculty of Biosciences, University of Joensuu, FI-80101 Joensuu, Finland, ${ }^{2}$ Department of Ecology and Environmental Science, Umeå \\ University, SE-90187 Umeå, Sweden and ${ }^{3}$ Forschungsinstitut Senckenberg, D-60325 Frankfurt am Main, Germany \\ Email: Tommi Nyman* - Tommi.Nyman@joensuu.fi; Folmer Bokma - Folmer.Bokma@emg.umu.se; Jens- \\ Peter Kopelke - Jens.Kopelke@senckenberg.de \\ * Corresponding author
}

Published: I November 2007

BMC Biology 2007, 5:49 doi:10.1 I86/1741-7007-5-49

This article is available from: http://www.biomedcentral.com/174I-7007/5/49

(C) 2007 Nyman et al; licensee BioMed Central Ltd.

This is an Open Access article distributed under the terms of the Creative Commons Attribution License (http://creativecommons.org/licenses/by/2.0), which permits unrestricted use, distribution, and reproduction in any medium, provided the original work is properly cited.
Received: 24 September 2007

Accepted: I November 2007

\begin{abstract}
Background: Plants, plant-feeding insects, and insect parasitoids form some of the most complex and species-rich food webs. According to the classic escape-and-radiate (EAR) hypothesis, these hyperdiverse communities result from coevolutionary arms races consisting of successive cycles of enemy escape, radiation, and colonization by new enemy lineages. It has also been suggested that "enemy-free space" provided by novel host plants could promote host shifts by herbivores, and that parasitoids could similarly drive diversification of gall form in insects that induce galls on plants. Because these central coevolutionary hypotheses have never been tested in a phylogenetic framework, we combined phylogenetic information on willow-galling sawflies with data on their host plants, gall types, and enemy communities.

Results: We found that evolutionary shifts in host plant use and habitat have led to dramatic prunings of parasitoid communities, and that changes in gall phenotype can provide "enemy-free morphospace" for millions of years even in the absence of host plant shifts. Some parasites have nevertheless managed to colonize recently-evolved gall types, and this has apparently led to adaptive speciation in several enemy groups. However, having fewer enemies does not in itself increase speciation probabilities in individual sawfly lineages, partly because the high diversity of the enemy community facilitates compensatory attack by remaining parasite taxa.

Conclusion: Taken together, our results indicate that niche-dependent parasitism is a major force promoting ecological divergence in herbivorous insects, and that prey divergence can cause speciation in parasite lineages. However, the results also show that the EAR hypothesis is too simplistic for species-rich food webs: instead, diversification seems to be spurred by a continuous stepwise process, in which ecological and phenotypic shifts in prey lineages are followed by a lagged evolutionary response by some of the associated enemies.
\end{abstract}

\section{Background}

One of the main challenges of biological research is to understand the evolutionary assembly and maintenance of complex, multitrophic food webs $[1,2]$. The classic escape-and-radiate (EAR) hypothesis [3] envisions the current remarkable diversity of plants and herbivorous insects $[4,5]$ as a result of a cyclic coevolutionary process: a plant lineage that acquires a new defensive trait (e.g., a 
toxic chemical) becomes free to proliferate and rapidly divides into multiple descendant lineages $[3,6]$. Over time, the defenses of the new clade are overcome by some insect species, which now enter a vacant adaptive zone and diversify to exploit the species of the hitherto herbivore-free plant group $[3,7]$. A new cycle of diversification starts whenever a novel defense evolves in one of the plant lineages.

Although the EAR hypothesis was originally formulated in terms of plants and herbivores, it has recently been suggested that a concurrent EAR process operates between plant-feeding insects and their associated parasitoids $[1,8]$. Parasitic insects typically inflict heavy mortality on herbivore populations $[9,10]$, and the specialized host use of both insect herbivores and parasitoids leads to the intriguing possibility that these hyperdiverse interaction networks are created "from within", that is, by diversifying effects that are transmitted or even amplified through many trophic levels. "Bottom-up" speciation cascades could result if diversification of plants spurs speciation of herbivores $[5,7,11]$ that, in turn, leads to increased resource diversity for associated parasitoids [2,12,13]. "Top-down" diversifying forces could be equally important if parasitoids use plants as cues for finding their host insects; in such cases, an evolutionary shift to a novel host plant could provide "enemy-free space" for the herbivores $[9,14,15]$. Release from enemies could accelerate diversification in the herbivore lineage that, in turn, would create more possibilities for parasitoid speciation.

Diversifying selection exerted by natural enemies might similarly underlie the unusual diversity of many gallinducing insect groups. The ability to induce galls on plants has evolved convergently in dozens of distantly related insect taxa and, as a result of spectacular adaptive radiations, many of these groups contain hundreds of species that differ markedly with respect to their host plant use and gall morphology [16,17]. Phylogeny-based comparative studies have demonstrated that galls represent "extended phenotypes" of the gallers, meaning that gall form and location is determined mainly by the galling insects and not by their host plants $[17,18]$. Because galler parasitoids have to penetrate a protective wall of modified plant tissue in order to gain access to their victims, Stone and Schönrogge [17] recently concluded that morphology-dependent parasitism remains the most plausible adaptive explanation for the diversification of gall form, but they also noted that the needed phylogenetic tests are lacking.

Despite its intuitive appeal, the EAR hypothesis has never been tested in a phylogenetic framework [8]. Therefore, we investigated how phylogenetic patterns of parasitism and diversification in gall-inducing sawflies belonging to the nematine subtribe Euurina (Hymenoptera: Tenthredinidae) conform to the predictions of the hypothesis. Euurina sawflies induce leaf folds or rolls, or various closed galls on willows (Salix spp.) and, at over 400 species, the subtribe includes over 10 times more species than its sister group with larvae that feed externally on leaves $[19,20]$. Their main sources of mortality are larvae of parasitoids (that feed on galler larvae) and parasitic inquilines (that consume gall tissues but kill the sawfly larvae in the process) $[19,21]$. In all, the associated enemy complex comprises nearly 100 species that belong to 17 families in four insect orders $[19,22]$. Sawfly gallers are particularly suited for studying the evolutionary assembly of complex food webs, because while each galler species is typically a specialist on a single willow species, all of the seven main types of closed galls can be found on multiple willow hosts $[19,21]$; this cross-replication of willows and galls makes it possible to tease apart the respective effects of host plants and gall phenotypes on the composition of the enemy community attacking each galler species.

\section{Results and discussion}

As a first step, we reconstructed the phylogenetic tree of willow gallers on the basis of DNA sequence data from two mitochondrial genes (see Methods). The strongly supported phylogeny (Figure 1) confirms earlier results that species inducing closed galls evolved from external-feeding sawfly lineages via leaf folders $[18,20]$, and demonstrates that the galler community on any given willow species is a collection of sawflies inducing different galls that have colonized the host, or one of its ancestors, at different time intervals.

Contrasting the galler phylogeny with quantitative data on the mortalities inflicted by inquiline and parasitoid species shows that evolutionary changes in many different ecological traits can lead to full or partial release from natural enemies (Figure 2). Permutation tests demonstrate a strong correlation between galler phylogeny and specieslevel enemy communities (Figure $3 \mathrm{~A}, \mathrm{p}<0.0001$ ), which mainly follows from the fact that the largest differences in enemy communities occur among gall types, which are likewise strongly conserved with respect to the galler tree. Constraining permutations of species-level enemy communities to occur only within gall types also leads to longer data lengths (Figure $3 \mathrm{~B}, \mathrm{p}=0.0022$ ), but the increase tends to be less pronounced than in unconstrained randomizations. Within gall-type groups, enemy communities in many cases differ markedly among willow species, but a statistically significant host plant effect extends also across gall-type boundaries (Figure 3C; paired samples $t$ test, $t=-1.72,95 \%$ c.i. $-\infty$ to -0.104 , onetailed $p=0.043$ ). These results are robust enough to be found also in randomization tests based on qualitative 


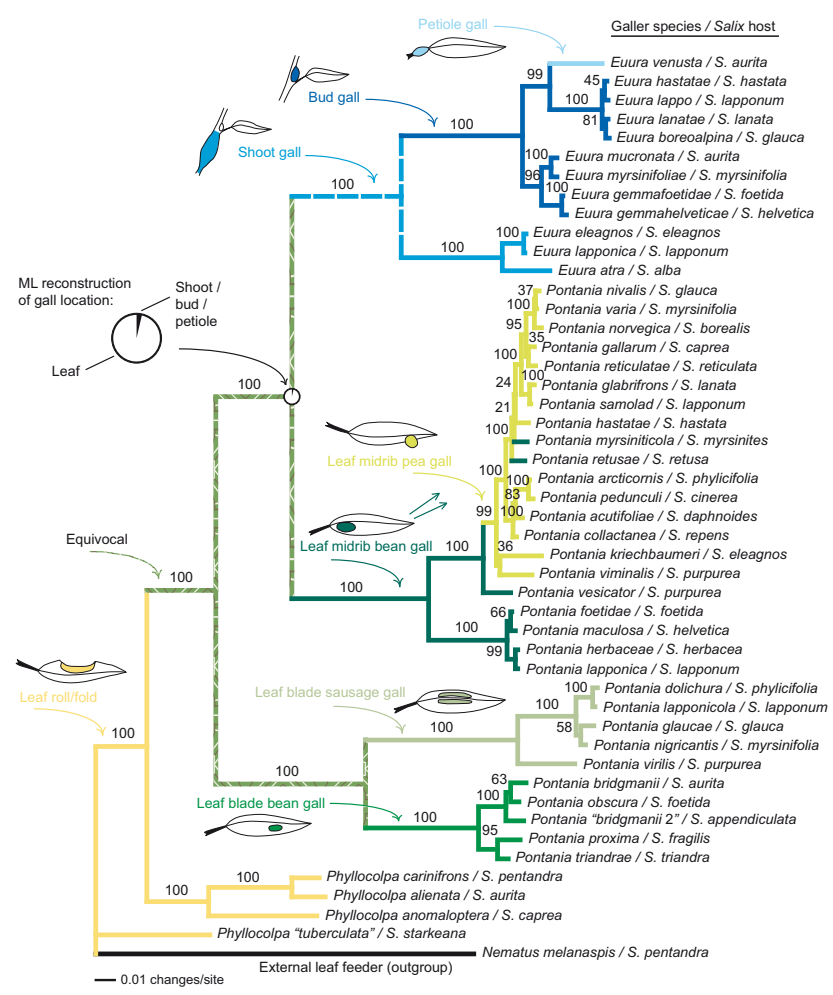

Figure I

Evolutionary diversification of gall morphology and host plant use in willow-galling sawflies. The tree is according to a Bayesian phylogenetic analysis of I 528 bp of DNA sequence data from two mitochondrial genes (see Methods), numbers above branches show posterior probabilities of clades. Host plants are indicated after the sawfly species names. Ancestral gall types were reconstructed using Accelerated transformations parsimony optimization (the ancestral state of the Euura clade is equivocal, but it was probably shoot galling [18]). The pie diagram at the node between Euura and their sister group shows the relative likelihood of different gall locations as reconstructed by maximum likelihood.

(presence/absence) data on enemy communities (Figure $4 \mathrm{~A}-\mathrm{C})$.

Sawflies inducing identical galls on different host species are in many cases attacked by very different parasite assemblages (Figure 2), which indicates that directional selection coefficients imposed by natural enemies can be extremely strong during host plant shifts. For example, host-provided enemy-free space evidently can be found especially on several distantly related willow species that grow in sub-arctic and arctic-alpine habitats (e.g., S. lapponum, S. reticulata, and S. myrsinites) where, for example, the predominantly southern inquilines Curculio crux (Coleoptera: Curculionidae) and Hydriomena ruberata (Lepidoptera: Geometridae) occur only rarely (Figure 2). Conversely, leaf gallers on northern willows generally suffer from increased attack by the parasitic wasps Shawiana lapponica and Lathrostizus flexicauda (Hymenoptera:
Ichneumonidae). Contrasting selection pressures caused by spatial and temporal variation in enemy communities [22-24] could explain why some prevalent and seriously lethal parasite species have been both lost and gained during the diversification of leaf-galling sawfly lineages (Figure 2).

However, the most dramatic shift in enemy communities coincides with the evolutionary transition from the ancestral condition of leaf galling to gall induction on shoots, buds, and petioles (Figures 1 and 2). This seemingly minor change in gall phenotype, which occurred at least six million years ago [25], led to a near-complete elimination of parasitic inquilines and to a coincident pruning of the parasitoid community (Figures 2 and 5A; Table 1), demonstrating that gall-inducing insects can find immediate and long-lasting "enemy-free morphospace" even in the absence of host plant shifts. The community plot shows that the novel gall types were subsequently tracked and colonized by parasitic lineages that apparently were derived mainly from the ancestral pool of enemies. In accordance with the EAR hypothesis, at least five probable cases of adaptive splitting along gall-type boundaries can be identified in the parasitic wasp genera Lathrostizus (Ichneumonidae), Pteromalus (Pteromalidae), and Eurytoma (Eurytomidae) (Figure 2), probably because successful attack on different galls requires specialized adaptations in the parasitoids' search behaviors and ovipositor structures $[10,22,24]$.

The central prediction of the EAR hypothesis is that escapes from enemies trigger rapid radiations in prey lineages $[3,6,8]$, but our phylogenetic results (Figures 1 and 2) directly contradict this proposition. Current estimates $[19,21]$ of species numbers in the conspicuously parasitepoor Euura clade (ca. 100 spp.) are lower than those of their enemy-rich sister group composed of leaf midrib bean and pea gallers (ca. 150 spp.), and both of these clades contain more species than the monophyletic group comprising the enemy-rich leaf blade bean and sausage gallers (ca. 80 spp.). Additional comparative studies involving other insect taxa are needed to confirm this conflicting pattern, but it has been argued that the prediction of elevated speciation rates in enemy-free lineages has a weak theoretical basis [8], and our data suggest two explanations for the absence of notable speciation bursts. First, in complex food webs, release from some enemies can be quickly compensated by an increase in the severity of attack by the remaining ones, which is evidenced by a lack of association between numbers of parasite species and rates of parasite-inflicted mortality in comparisons across galler species (Pearson's $r=0.165, \mathrm{p}=0.291$; Figure 5B, Table 2). Less obvious zero-sum games of survival are also possible, so that while overall rates of parasitism are slightly lower in Euura species than in leaf gallers, the ben- 


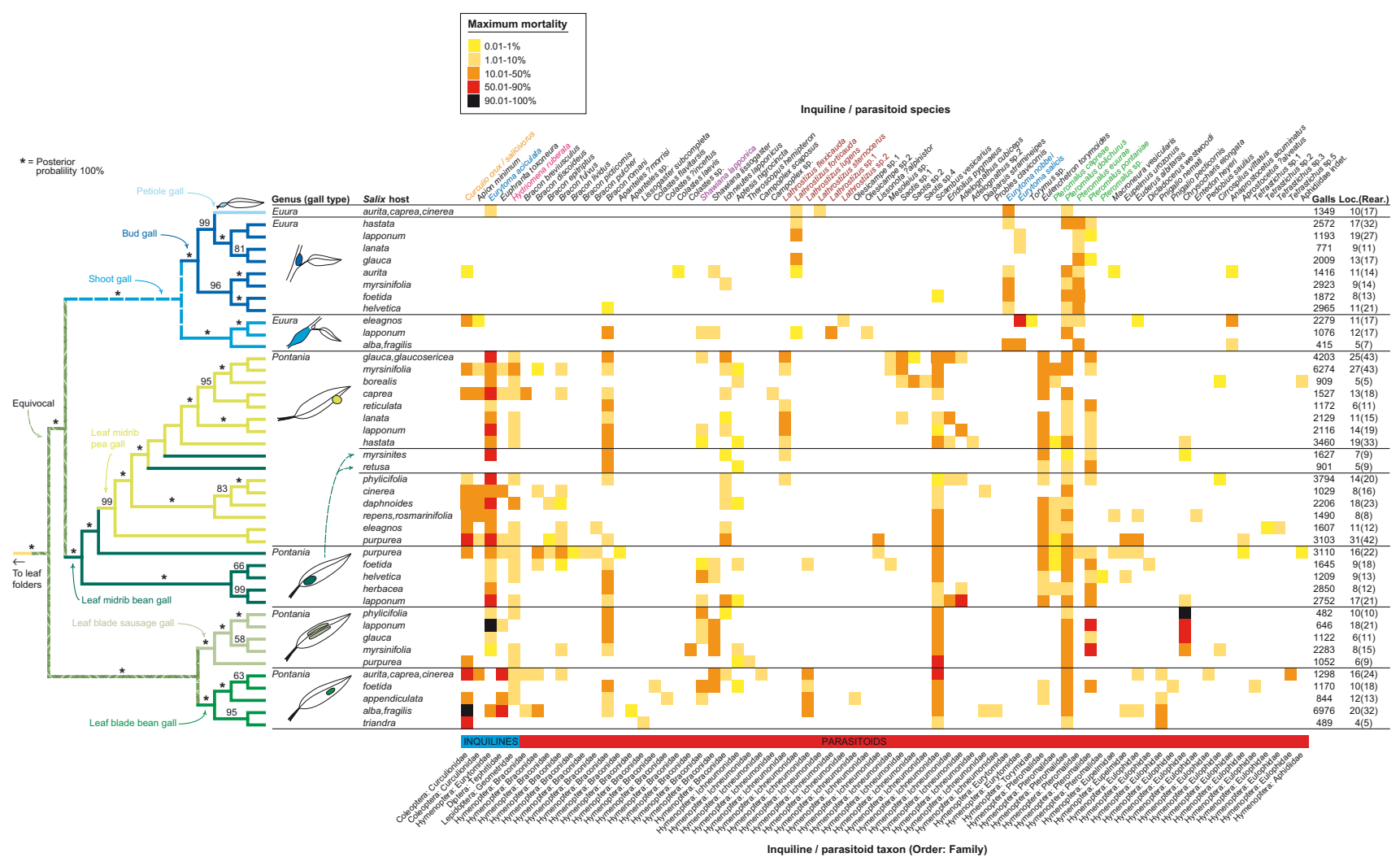

Figure 2

Maximum rates of mortality inflicted by 72 inquiline and parasitoid species on $\mathbf{4 3}$ willow-galling sawfly species in relation to the phylogeny, gall morphology, and host plants of the gallers. Sawfly names have been omitted, but their order is the same as in Figure I. Each column in the plot represents one inquiline or parasitoid species, maximum rates of parasitism observed in extensive population rearings of each galler species [2I,22] are indicated by the colour of the cells (see legend). See Additional file I for exact rates of parasitism. Enemy species and genera mentioned in the text are highlighted by a coloured font, and the taxon to which each parasite species belongs is indicated below the matrix (note that the wasp genus Eurytoma includes two parasitoids and an inquiline). Numbers of dissected galls, collection localities, and population rearings are given in the last two columns. Numbers above branches on the tree show Bayesian posterior probabilities (only values $\geq 50 \%$ shown, asterisks denote clades with a $100 \%$ posterior probability).

efit seems to be offset by an increased susceptibility to defence reactions on behalf of the host plants $[19,22]$. Second, if prey species are (like most plant feeding insects $[4,5])$ themselves resource specialists, a moderate enemy pressure might promote the prey's colonization of novel niches (e.g., plants $[9,14,15])$ and thus facilitate ecological speciation in prey lineages. This could especially be the case if geographical variation in enemy assemblages drives different populations of widespread prey species into using different resources.

\section{Conclusion}

Coevolutionary studies on parasitoids and their prey commonly focus on physiological defenses and counterdefenses [26], but our results clearly show that ecological traits constitute a central part of the defensive arsenal of herbivorous insects. Prior to a niche shift, an evolving prey lineage must exhibit a polymorphism in resource use, which can be followed by quick fixation of one of the alternative states whenever different resources are associated with different enemy attack patterns. Furthermore, our finding that several parasitoid lineages have responded to gall-type divergence by adaptive speciation provides strong support for suggestions $[1,2,8]$ that coevolutionary arms races have played an important role in the generation of the unusual diversity of herbivorous insects and parasitoids. Nevertheless, our data also indicate that in its classic form the EAR hypothesis is too simplistic to explain reciprocal diversification effects in complex food webs, in which escapes from enemies will tend to be too brief to lead to the predicted speciation bursts. Instead, the observed patterns of parasitism and diversification are consistent with a scenario of stepwise antagonistic coevolution: colonization of new ecological niches by prey lineages is being continuously driven by temporary relief from parasitism, after which an evolu- 

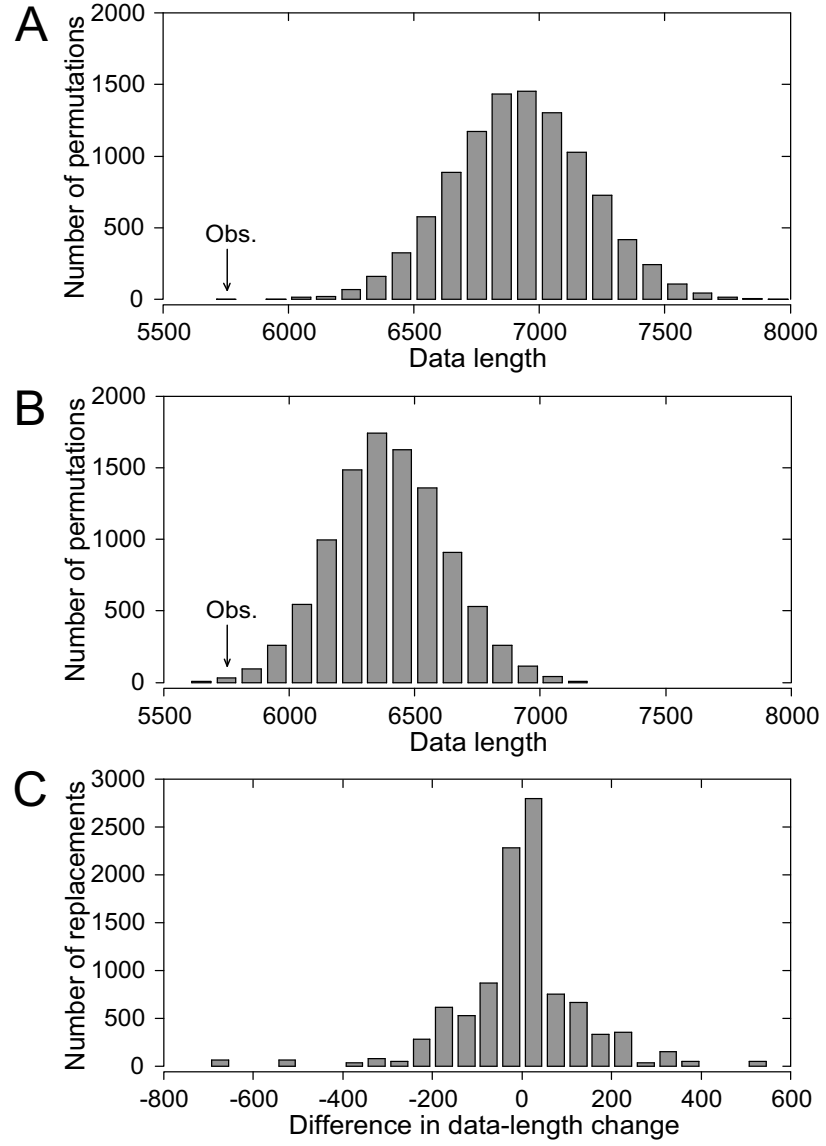

Figure 3

Distributions of data lengths resulting from random permutations of galler enemy communities in relation to the galler phylogeny. In (A) and (B), the arrow indicates the length of the observed quantitative parasitism data, as calculated on the basis of the galler topology in Figure 2. (A) Distribution of data lengths when enemy communities (rows) are permuted 10000 times across the whole galler phylogeny. (B) Distribution of data lengths when enemy communities are similarly permuted within gall-type groups. (C) Distribution of the difference in the absolute change in data length when the enemy complex of a galler species is replaced by those of two species from another gall type, of which only one also has a different host willow. Negative values of the difference indicate that the change in data length is smaller when the replacing species occurs on the same host plant (see Methods).

tionary response by some of the associated enemies returns mortalities to normal levels. In its complexity, the willow-galler-parasite food web is representative of many antagonistic networks in which specialized interactions link species across multiple trophic levels. A close integration of ecological and evolutionary research is clearly needed if the origins of such networks are to be fully understood.
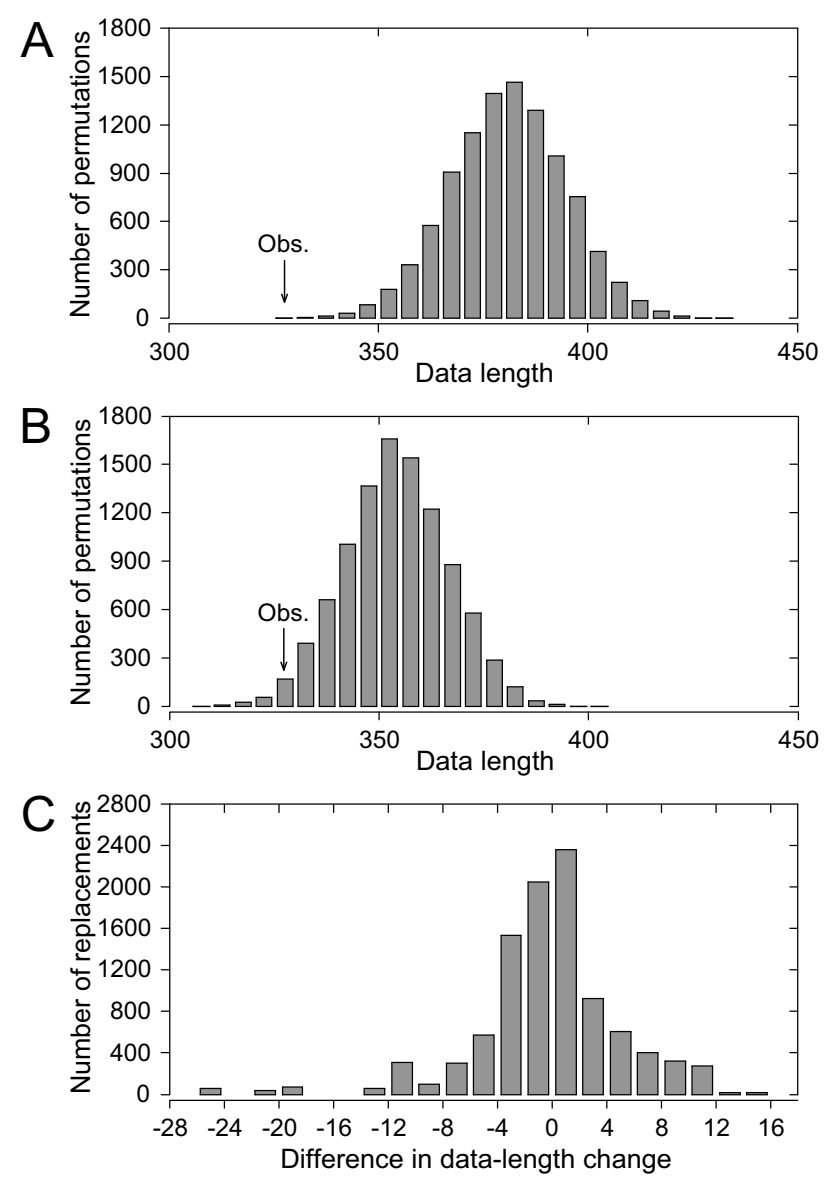

Figure 4

Distributions of data lengths resulting from random permutations of galler enemy communities in relation to the galler phylogeny. The histograms show the distributions of data lengths when qualitative (i.e., presence/absence) data on enemy species are used instead of the quantitative rates of mortality used in Figure 3. In (A) and (B), the arrow indicates the length of the observed qualitative parasitism data, as calculated on the basis of the galler topology in Figure 2. (A) Distribution of data lengths when enemy communities (rows) are permuted 10000 times across the whole galler phylogeny $(p<0.000 \mathrm{I})$. (B) Distribution of data lengths when enemy complexes are similarly permuted within gall-type groups $(p=0.0158)$. (C) Distribution of the difference in the absolute change in data length when the enemy complex of a galler species is replaced by those of two species from another gall type, of which only one also has a different host willow (see Methods). Negative values of the difference indicate that the change in data length is smaller when the replacing species occurs on the same host plant (paired samples $t$ test, $t=-4.93,95 \%$ c.i. $-\infty$ to 0.174 , one-tailed $p<0.001)$.

\section{Methods}

Parasitism data and taxon sampling

Enemy rearing methods and collection localities of galler population samples have been described previously $[21,22]$. In brief, populations were sampled extensively throughout Europe between 1981 and 1998, and galls were opened to score the presence of galler or parasitoid/ 
Table I: Effects of gall type and sample size (= number of galls collected) on the number of parasitoid species observed attacking each galler species

\begin{tabular}{llllll}
\hline Source & Type III sum of squares & df & Mean square & $F$ & P Value \\
\hline Corrected model & $592.188^{*}$ & 6 & 98.698 & 10.360 & $<0.001$ \\
Intercept & 64.579 & 1 & 64.579 & 6.779 & 0.013 \\
Number of galls & 166.368 & 1 & 166.368 & 17.464 & $<0.001$ \\
Gall type & 382.832 & 5 & 76.566 & 8.037 & $<0.001$ \\
Error & 333.431 & 35 & 9.527 & & \\
Total & 5046.000 & 42 & & & \\
Corrected total & 925.619 & 4 I & & & \\
\hline
\end{tabular}

df, degrees of freedom

Gall type was included as a fixed factor and sample size as a covariate in the ANCOVA model. Sample sizes were In-transformed prior to the analysis, because logarithmic regressions produced more biologically realistic results and a better fit to the observed data (Figure 5A) than did linear regressions with untransformed sample sizes.

$* \mathrm{R}^{2}=0.640$ (adjusted $\mathrm{R}^{2}=0.578$ ).

A

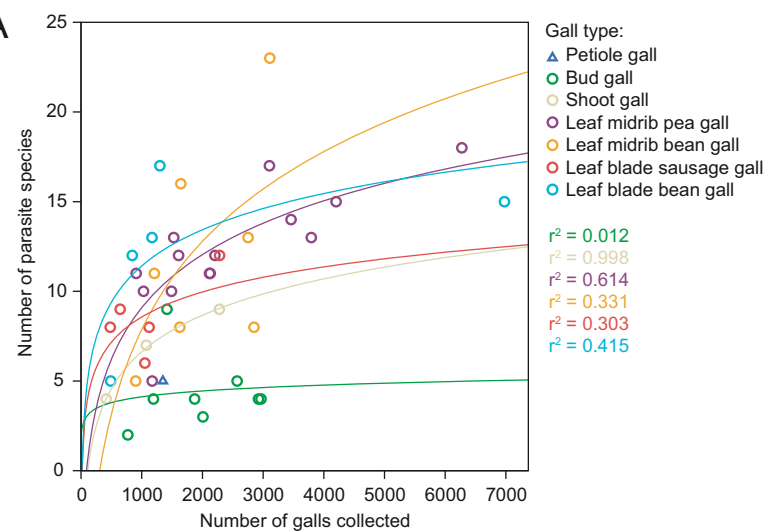

B

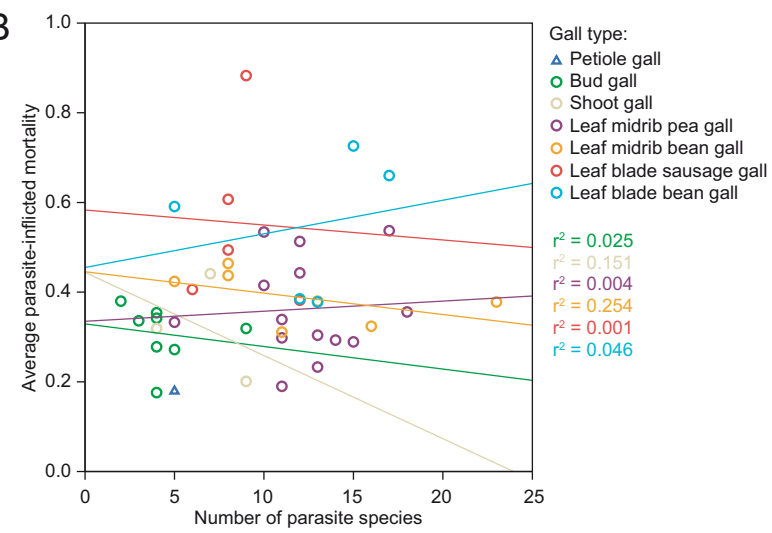

Figure 5

Factors explaining numbers of enemy species and parasite-inflicted mortalities in individual galler species. Each point in the plots represents one galler species. (A) Numbers of associated enemy species in relation to gall types and sample sizes. Lines show logarithmic regression curves for each gall type. (B) Average parasite-inflicted mortalities of individual galler species [22] in relation to their gall types and numbers of associated parasite species. Lines are not shown for petiole gallers that are represented by a single species (triangle). ANCOVA results for $(A)$ and (B) are given in Tables I and 2, respectively. inquiline larvae. Enemy larvae were classified to preliminary morphospecies, and the identity of each morphospecies was determined by connecting them to adults emerging after hibernation. The severity of parasitism by each enemy species in each galler species was defined as the maximum observed level of mortality inflicted in the population samples (see Additional file 1 for exact rates of parasitism), which is a valid indicator of the potential importance of natural enemies [10]. To control for sampling effects, our phylogenetic analysis includes the 43 galler species (Table 3 ) that have parasitism data from at least four locations and a total sample size of over 400 galls. In accordance with previous results $[18,25]$, we used the free-feeding nematine Nematus melanaspis and four leaf-folding or -rolling Phyllocolpa species as outgroups in the phylogenetic analyses.

\section{Phylogeny reconstruction}

DNA sequence data was generated for 1528 base pairs of two mitochondrial genes (cytochrome oxidase I: 810 bp; cytochrome $b$ : $718 \mathrm{bp}$ ) using protocols described previously $[18,25]$. All sequences have been deposited in GenBank under accession numbers DQ302205, DQ302212, and EU083911-EU084004. Modeltest 3.5 [27] was used in conjunction with PAUP* $4.0 \mathrm{~b} 10$ [28] to select the $\mathrm{GTR}+\mathrm{I}+\Gamma_{4}$ substitution model subsequently implemented in a Bayesian phylogenetic analysis in MrBayes 3.1.1 [29]. Two parallel runs employing default priors and consisting of four incrementally heated chains $(t=0.2)$ were run for six million generations while sampling trees from the current cold chain every 100 generations, and 110002 postburn-in trees were used to calculate a Bayesian consensus tree. Because the tree is strongly supported and maximum-parsimony and maximum-likelihood analyses of the sequence data led to near-identical results, only the Bayesian tree was used in the permutation tests described below. 
Table 2: Effects of gall type and number of associated parasite species on average mortalities in individual galler species

\begin{tabular}{llllll}
\hline Source & Type III sum of squares & df & Mean square & $F$ & P Value \\
\hline Corrected model & $0.378^{*}$ & 6 & 0.063 & 3.834 & 0.005 \\
Intercept & 2.431 & 1 & 2.431 & 147.756 & $<0.001$ \\
Number of parasite species & 0.001 & 1 & 0.001 & 0.040 & 0.843 \\
Gall type & 0.362 & 5 & 0.072 & 4.401 & 0.003 \\
Error & 0.576 & 35 & 0.016 & & \\
Total & 20.437 & 42 & & & \\
Corrected total & 0.954 & 41 & & &
\end{tabular}

Gall type was included as a fixed factor and number of parasite species as a covariate in the ANCOVA model (see Figure 5B). Mortalities were arcsine square root transformed prior to the analysis.

$* \mathrm{R}^{2}=0.397$ (adjusted $\mathrm{R}^{2}=0.293$ ).

\section{Character evolution analyses and statistical tests}

Ancestral gall types were inferred by accelerated transformations parsimony optimization [30], and ancestral gall locations (leaf, shoot, bud, or petiole) by maximum likelihood (ML) reconstruction in Mesquite 1.11 [31]. In the ML analysis, we employed an Mk1 model (= equal forward and reverse rates) after pruning the external-feeding outgroup from the galler tree. Because maximum rates of parasitism by different enemy species are not independent in galler population samples, we treated species-level enemy communities ( = rows in the table in Additional file 1) as the observation for each galler species, and then devised three alternative permutations of enemy communities over galler species to test correlations between the parasitism matrix and the galler phylogeny. If parasite communities tend to be similar among closely related galler species, the length of the enemy data, as calculated on the basis of the galler topology, will be shorter than expected from random assignment. Data length [32] was calculated first from the observed data, and subsequently from 10000 random permutations of enemy communities over galler species. The probability that by chance data is as short as observed is calculated by comparing the observed data length with the distribution of permuted data lengths. Possible phylogenetic correlations within gall types were tested by restricting the permutations to occur only among sawfly species that induce similar galls.

To test whether an effect of the willow host species extends across gall-type boundaries, we used a paired replacement procedure: the enemy community of a randomly chosen galler species was replaced with the enemy communities of two randomly selected species. Those two species had the same gall type (different from that of the species being replaced) but only one of those two had a different host plant. The other species thus had the same host plant as the species being replaced. The absolute change in data length was calculated for each of the two replacements, and subsequently the difference in datalength change was calculated between the two replacements. If the replacement with a species that shares the host plant with the species being replaced results in a smaller absolute change in data length, the difference in absolute data length change becomes negative (and conversely, positive if the species not sharing the host plant yields a smaller data-length change). The distribution of differences in absolute tree-length change resulting from 10000 such paired replacements was evaluated against the null hypothesis (= mean change in absolute data length equal) using a paired samples $t$ test. For the purposes of the species effect tests, willows belonging to two species complexes consisting of sister taxa with extensive hybridization (S. alba and S. fragilis; and S. caprea, S. aurita, and $S$. cinerea) were synonymized under two "superspecies". All permutation and replacement tests were performed in Matlab (The MathWorks, Inc., 3 Apple Hill Drive, Natick, MA 01760-2098, USA), see Additional file 2 for the scripts used for the tests. ANCOVA tests used for testing factors influencing numbers of associated parasitoid species and rates of parasite-inflicted mortality were performed using SPSS for Windows 14.0 (SPSS, Inc., 233 S. Wacker Drive, Chicago, IL 60606-6307, USA).

\section{Authors' contributions}

$\mathrm{TN}$ was responsible for research planning, sequencing, phylogeny reconstruction, and writing. Statistical tests were devised by TN and FB and programmed by FB. Galler population sampling and enemy rearings were performed by JPK. All authors participated in the writing process. All the authors have read and approved the final manuscript.

\section{Additional material}

\section{Additional file 1}

Excel file showing maximum rates of mortality inflicted by each inquiline and parasitoid species on each galler species.

Click here for file

[http://www.biomedcentral.com/content/supplementary/17417007-5-49-S1.xls] 
Table 3: Taxa and samples used in the study, their gall types, willow hosts, and collection data

\begin{tabular}{|c|c|c|c|c|c|c|}
\hline Genus (gall type) & Species & Salix host & Sample code & Specimen & Location and date & Collector \\
\hline \multirow[t]{5}{*}{ Pontania (Leaf blade sausage gall) } & dolichura & phylicifolia & 04I5I/QI & Larva & Korvua, Finland, 9.vii.2004 & T. Nyman \\
\hline & glaucae & glauca & 97/94/Q2 & Larva & Kilpisjärvi, Finland, 4.viii.I 997 & T. Nyman \\
\hline & lapponicola & lapponum & 05I49/ZI & Larva & Nuorgam, Finland, 3.vii.2005 & T. Nyman \\
\hline & nigricantis & myrsinifolia & 04236/Q3 & Larva & Hintertux, Austria, 8.viii.2004 & T. Nyman \\
\hline & virilis & purpurea & $05018 / Y 2$ & Larva & Kiesnitz, Oder, Germany, I8.v.2005 & A. Liston \\
\hline \multirow{5}{*}{ Pontania (Leaf blade bean gall) } & bridgmanii & aurita, caprea, cinerea & 97076/Q4 & Larva & Mekrijärvi, Finland, 22.vii. I997 & T. Nyman, A. Zinovjev \\
\hline & proxima & alba, fragilis & 04388/Q5 & Larva & Oulu, Finland, 8.x.2004 & T. Nyman \\
\hline & triandrae & triandra & 97455/Q6 & Larva & Keminmaa, Finland, 29.vii. 1997 & T. Nyman \\
\hline & obscura & foetida & $04264 / \times 6$ & Larva & Hintertux, Austria, 9.viii.2004 & T. Nyman \\
\hline & "bridgmanii 2" & appendiculata & $04 \mid 25 / X 1$ & Larva & Vent-Sölden, Austria, 20.vi.2004 & T. Nyman \\
\hline \multirow{6}{*}{ Pontania (Leaf midrib bean gall) } & foetidae & foetida & 04263/Q9 & Larva & Hintertux, Austria, 9.viii.2004 & T. Nyman \\
\hline & herbaceae & herbacea & 98230/QX & Larva & Abisko, Sweden, I2.viii. 1998 & T. Nyman \\
\hline & lapponica & lapponum & $98308 / R I$ & Larva & Abisko, Sweden, I6.viii.I998 & T. Nyman \\
\hline & maculosa & helvetica & 04308/R2 & Larva & Vent, Austria, I2.viii.2004 & T. Nyman \\
\hline & retusae & retusa & $04243 / R 3$ & Larva & Hintertux, Austria, 8.viii.2004 & T. Nyman \\
\hline & vesicator & purpurea & 04200/R5 & Larva & Obergurgl, Austria, 5.viii.2004 & T. Nyman \\
\hline \multirow[t]{15}{*}{ Pontania (Leaf midrib pea gall) } & acutifoliae daphnoides & daphnoides & 97490/R6 & Larva & Latvia, 22.viii.1997 & H. Roininen, A. Zinovjev \\
\hline & arcticornis & phylicifolia & $98328 / R 7$ & Larva & Kilpisjärvi, Finland, I8.viii.1998 & T. Nyman \\
\hline & collactanea & repens, rosmarinifolia & $04 \mid 24 / R 8$ & Larva & Blåvand, Denmark, I6.vi.2004 & T. Nyman \\
\hline & gallarum & caprea & $98132 / R 9$ & Larva & Joensuu, Finland, 21.vii.1998 & T. Nyman \\
\hline & glabrifrons & lanata & $98335 / R X$ & Larva & Kilpisjärvi, Finland, 19.viii.1998 & T. Nyman \\
\hline & hastatae & hastata & $01153 / \mathrm{SI}$ & Larva & Kilpisjärvi, Finland, 9.viii.200I & T. Nyman \\
\hline & kriechbaumeri & eleagnos & $04333 / S 2$ & Larva & Pertisau, Austria, I3.viii.2004 & T. Nyman \\
\hline & myrsiniticola & myrsinites & $98364 / \mathrm{S} 3$ & Larva & Kilpisjärvi, Finland, 23.viii.I998 & T. Nyman \\
\hline & nivalis & glauca, glaucosericea & $98346 / S 4$ & Larva & Kilpisjärvi, Finland, 20.viii. 1998 & T. Nyman \\
\hline & norvegica & borealis & $98374 / \mathrm{S} 5$ & Larva & Kilpisjärvi, Finland, 26.viii. 1998 & T. Nyman \\
\hline & pedunculi & cinerea & $98393 / S 6$ & Larva & Janakkala, Finland, I3.viii.1998 & A. Zinovjev \\
\hline & reticulatae & reticulata & $04240 / S 7$ & Larva & Hintertux, Austria, 8.viii.2004 & T. Nyman \\
\hline & samolad & lapponum & $98373 / \mathrm{S} 8$ & Larva & Kilpisjärvi, Finland, 25.viii. 1998 & T. Nyman \\
\hline & varia & myrsinifolia & $98198 / Z 2$ & Larva & Joensuu, Finland, 20.vii.1998 & T. Nyman \\
\hline & viminalis & purpurea & $04226 / S X$ & Larva & Sölden, Austria, 7.viii.2004 & T. Nyman \\
\hline \multirow[t]{8}{*}{ Euura (Bud gall) } & hastatae & hastata & 97497/TI & Larva & Kilpisjärvi, Finland, I3.viii.I997 & T. Nyman \\
\hline & lanatae & lanata & $98024 / T 2$ & Q, ex larva & Kilpisjärvi, Finland, I5.viii. 1997 & T. Nyman \\
\hline & lappo & lapponum & $98362 / \mathrm{T} 3$ & Larva & Kilpisjärvi, Finland, 23.viii. 1998 & T. Nyman \\
\hline & mucronata & aurita & 04385/T4 & Larva & Oulu, Finland, 8.ix.2004 & T. Nyman \\
\hline & gemmafoetidae & foetida & 04360/T5 & Larva & Hintertux, Austria, 9.viii.2004 & T. Nyman \\
\hline & boreoalpina & glauca & $98363 / T 6$ & Larva & Kilpisjärvi, Finland, 23.viii. 1998 & T. Nyman \\
\hline & gemmahelveticae & helvetica & $04363 / \mathrm{TT}$ & Larva & Vent, Austria, 4.viii.2004 & T. Nyman \\
\hline & myrsinifoliae & myrsinifolia & $98371 / T 8$ & Larva & Kilpisjärvi, Finland, 23.viii. 1998 & T. Nyman \\
\hline \multirow[t]{3}{*}{ Euura (Shoot gall) } & atra & alba, fragilis & 97005/T9 & Q, ex pupa & Joensuu, Finland, 30.v.1997 & T. Nyman \\
\hline & eleagnos & eleagnos & $04357 / T X$ & Larva & Pertisau, Austria, I3.viii.2004 & T. Nyman \\
\hline & lapponica & lapponum & $98329 / \mathrm{VI}$ & Larva & Kilpisjärvi, Finland, 19.viii.1998 & T. Nyman \\
\hline Euura (Petiole gall) & venusta & $\frac{\text { aurita, caprea, }}{\text { cinerea }}$ & $00038 / V 3$ & Larva & Joensuu, Finland, 20.viii.2000 & T. Nyman \\
\hline
\end{tabular}

\begin{tabular}{|c|c|c|c|c|c|c|}
\hline Outgroups & & & & & & \\
\hline \multirow[t]{4}{*}{ Phyllocolpa (Leaf fold/roll) } & carinifrons ${ }^{1}$ & pentandra & $98120 / C 2$ & Larva & Kesälahti, Finland, I6.vii.1998 & H. Roininen \\
\hline & anomaloptera $^{2}$ & caprea & $97097 / \times 9$ & Larva & Joensuu, Finland, I8.vii.1997 & T. Nyman \\
\hline & alienata $^{3}$ & aurita, cinerea & $04055 / \times 5$ & Larva & Nymindegab, Denmark, I7.vi.2004 & T. Nyman \\
\hline & sp. (near tuberculata) & starkeana & 97063/E9 & Larva & St. Petersburg, Russia, I5.vi. I 997 & A. Zinovjev \\
\hline Nematus (External feeder) & melanaspis & pentandra & $01092 / D 6$ & Q, ex larva & Parikkala, Finland, 24.vi.200I & T. Nyman \\
\hline
\end{tabular}

In the case of oligophagous species, the host of the sampled individual is underlined

ISpecies name according to recent revision [33], previously named $P$. excavata.

2Species name according to recent revision [34], previously named $P$. leucapsis.

${ }_{3}^{3}$ ppecies name according to recent revision [35], previously named $P$. coriacea. 


\section{Additional file 2}

PDF file giving scripts used to perform permutation and replacement tests in Matlab

Click here for file

[http://www.biomedcentral.com/content/supplementary/17417007-5-49-S2.pdf]

\section{Acknowledgements}

We thank $H$ Roininen and $A$ Zinovjev for providing samples of missing galler species, and $\mathrm{H}$ Roininen, O-P Tikkanen and the two anonymous reviewers for comments that helped to improve the manuscript. Funding for this study was provided mainly by the Academy of Finland (project number I |893|).

\section{References}

I. Singer MS, Stireman JO III: The tri-trophic niche concept and adaptive radiation of phytophagous insects. Ecol Lett 2005 , 8:1247-1255

2. Kitching RL: Crafting the pieces of the diversity jigsaw puzzle. Science 2006, 3 I 3:1055-1057.

3. Ehrlich PR, Raven PH: Butterflies and plants: a study in coevolution. Evolution 1964, I 8:586-608.

4. Strong DR, Lawton JH, Southwood TRE: Insects on Plants: Community Patterns and Mechanisms Oxford: Blackwell Science; 1984

5. Novotny V, Drozd P, Miller SE, Kulfan M, Janda M, Basset Y, Weiblen GD: Why are there so many species of herbivorous insects in tropical rainforests? Science 2006, 3 I 3: I I I- I I8.

6. Farrell BD, Dussourd DE, Mitter C: Escalation of plant defense: do latex and resin canals spur plant diversification? Am Nat | 991, | 38:88|-900.

7. Farrell BD: "Inordinate fondness" explained: why are there so many beetles? Science 1998, 28 I:555-559.

8. Vamosi SM: On the role of enemies in divergence and diversification of prey: a review and synthesis. Can J Zool 2005, 83:894-910.

9. Price PW, Bouton CE, Gross P, McPheron BA, Thompson JN, Weis $A E$ : Interactions among three trophic levels: influence of plants on interactions between insect herbivores and natural enemies. Annu Rev Ecol Syst 1980, I I:4 | -65.

10. Hawkins BA: Pattern and Process in Host-Parasitoid Interactions Cambridge: Cambridge University Press; 1994.

II. Janz N, Nylin S, Wahlberg N: Diversity begets diversity: host expansions and the diversification of plant-feeding insects. BMC Evol Biol 2006, 6:4

12. Abrahamson WG, Blair CP, Eubanks MD, Morehead SA: Sequential radiation of unrelated organisms: the gall fly Eurosta solidaginis and the tumbling flower beetle Mordellistena convicta. Evol Biol 2003, 16:781-789.

13. Stireman JO III, Nason JD, Heard SB, Seehawer JM: Cascading hostassociated genetic differentiation in parasitoids of phytophagous insects. Proc R Soc Lond B 2006, 273:523-530.

14. Lill JT, Marquis RJ, Ricklefs RE: Host plants influence parasitism of forest caterpillars. Nature 2002, 4I 7: I70-I73.

15. Murphy SM: Enemy-free space maintains swallowtail butterfly host shift. Proc Natl Acad Sci USA 2004, I 0 I : | 8048- 18052

16. Price PW, Fernandes GW, Waring GL: Adaptive nature of insect galls. Environ Entomol 1987, 16:15-24.

17. Stone GN, Schönrogge K: The adaptive significance of insect gall morphology. TREE 2003, 1 8:512-522.

18. Nyman T, Widmer A, Roininen $\mathrm{H}$ : Evolution of gall morphology and host-plant relationships in willow-feeding sawflies (Hymenoptera: Tenthredinidae). Evolution 2000, 54:526-533

19. Roininen $\mathrm{H}$, Nyman T, Zinovjev AG: Biology, ecology, and evolution of gall-inducing sawflies (Hymenoptera: Tenthredinidae and Xyelidae). In Biology, Ecology, and Evolution of Gall-inducing Arthropods Edited by: Raman A, Schaefer CW, Withers TM. Enfield: Science Publishers; 2005:467-494.
20. Nyman T, Farrell BD, Zinovjev AG, Vikberg V: Larval habits, hostplant associations, and speciation in nematine sawflies (Hymenoptera: Tenthredinidae). Evolution 2006, 60: I622-I637.

21. Kopelke J-P: Gallenerzeugende Blattwespen Europas - Taxonomische Grundlagen, Biologie und Ökologie (Tenthredinidae: Nematinae: Euura, Phyllocolpa, Pontania). Cour Forsch-inst Senckenb 1999, 212:1-183.

22. Kopelke J-P: Natural enemies of gall-forming sawflies on willows (Salix spp.). Entomol Gener 2003, 26:277-3। 2.

23. Thompson JN: Specific hypotheses on the geographic mosaic of coevolution. Am Nat 1999:I-14.

24. Craig TP, Itami JK, Horner JD: Geographic variation in the evolution and coevolution of a tritrophic interaction. Evolution 2007, 6 I: I |37-I I52.

25. Nyman T, Zinovjev AG, Vikberg V, Farrell BD: Molecular phylogeny of the sawfly subfamily Nematinae (Hymenoptera: Tenthredinidae). Syst Entomol 2006, 3 I:569-583.

26. Pennacchio F, Strand MR: Evolution of developmental strategies in parasitic Hymenoptera. Annu Rev Entomol 2006, 5 I :233-258.

27. Posada D, Crandall KA: Modeltest: testing the model of DNA substitution. Bioinformatics 1998, |4:8|7-8|8.

28. Swofford DL: PAUP*. Phylogenetic Analysis Using Parsimony (*and Other Methods), version 40b/0 Sunderland: Sinauer; 2002.

29. Ronquist F, Huelsenbeck JP: MrBayes 3: Bayesian phylogenetic inference under mixed models. Bioinformatics 2003 , 19:1572-I574.

30. Swofford DL, Maddison WP: Reconstructing ancestral character states under Wagner parsimony. Math Biosci 1987, 87:199-229.

31. Maddison WP, Maddison DR: Mesquite: a modular system for evolutionary analysis, version I.II. 2006 [http://mesquite project.org].

32. Pauplin $\mathrm{Y}$ : Direct calculation of a tree length using a distance matrix. J Mol Evol 2000, 5 I:4 I-47.

33. Kopelke J-P: The species of the Phyllocolpa leucosticta-group in Europe (Hymenoptera: Tenthredinidae: Nematinae). Senckenb Biol 87:75-109.

34. Kopelke J-P: The species of the Phyllocolpa crassispina-, scotaspis-, and piliserra-group in Europe (Hymenoptera: Tenthredinidae: Nematinae). Senckenb Biol in press.

35. Kopelke J-P: The species of the Phyllocolpa leucapsis-group in Europe (Hymenoptera: Tenthredinidae: Nematinae). Senckenb Biol in press.
Publish with BioMed Central and every scientist can read your work free of charge

"BioMed Central will be the most significant development for disseminating the results of biomedical research in our lifetime. "

Sir Paul Nurse, Cancer Research UK

Your research papers will be:

- available free of charge to the entire biomedical community

- peer reviewed and published immediately upon acceptance

- cited in PubMed and archived on PubMed Central

- yours - you keep the copyright
BiolMedcentral 